\title{
PROSPECTS
}

\section{Post-PhD in an economic downturn}

Despite the gloom, this isn't a bad time to begin a scientific career. Keep your nerve, Bart Noordam and Patricia Gosling advise.

Many graduate students finishing their studies this year will be facing their post-PhD career with some dismay. They may not have given much thought to the next step until recently because, just a year ago, opportunities seemed abundant.

Now, jobs are evaporating as the global financial crisis escalates. Reading about job losses and redundancies in the news may cause graduates to panic and jump at any offer, forgetting their career plans of a year ago.

But new PhDs should keep in mind that they are at the very beginning of a long career. They need to consider the pros and cons of the different options available and not panic.

It is important to understand the broader trends that influence graduates' current assessment of job prospects. The present economic situation has had little immediate impact on (semi-) governmental organizations such as national labs and universities. To keep the economy going, most governments will try to support and preserve jobs in the public sector as long as possible. So the number of vacancies for a postdoctoral fellowship - a typical first step after a PhD - probably will not shrink dramatically in the short term.

Moreover, the long-term job outlook for graduates with natural-sciences training is still excellent in many regions. Take the Netherlands, for example. An article last October in Technomonitor (http://tinyurl.com/ $163 \mathrm{k} 6 \mathrm{k}$ ) reports a need during the next five years for an estimated 36,000 new academic employees trained in the natural sciences. The report is based on survey data from the Centre for Education and the Labour Market in Maastricht. Half of these new hires would replace existing employees (leaving for such reasons as retirement) and the other half is needed to meet demand based on expected growth. However, the data suggest that only 24,000 new graduates will be available to fill the vacancies.

A recent study commissioned by the German economics ministry found that young, skilled people are inadequately trained in academic subjects such as mathematics, natural sciences and technology. It estimates that Germany will lack up to 95,000 engineers and 135,000 scientists by 2014 (http://tinyurl.com/ox6slt).

In the long term, then, the Dutch numbers indicate that for every two graduates, three jobs are waiting. And estimated future vacancies could not be filled by the current workforce in either Holland or Germany. So

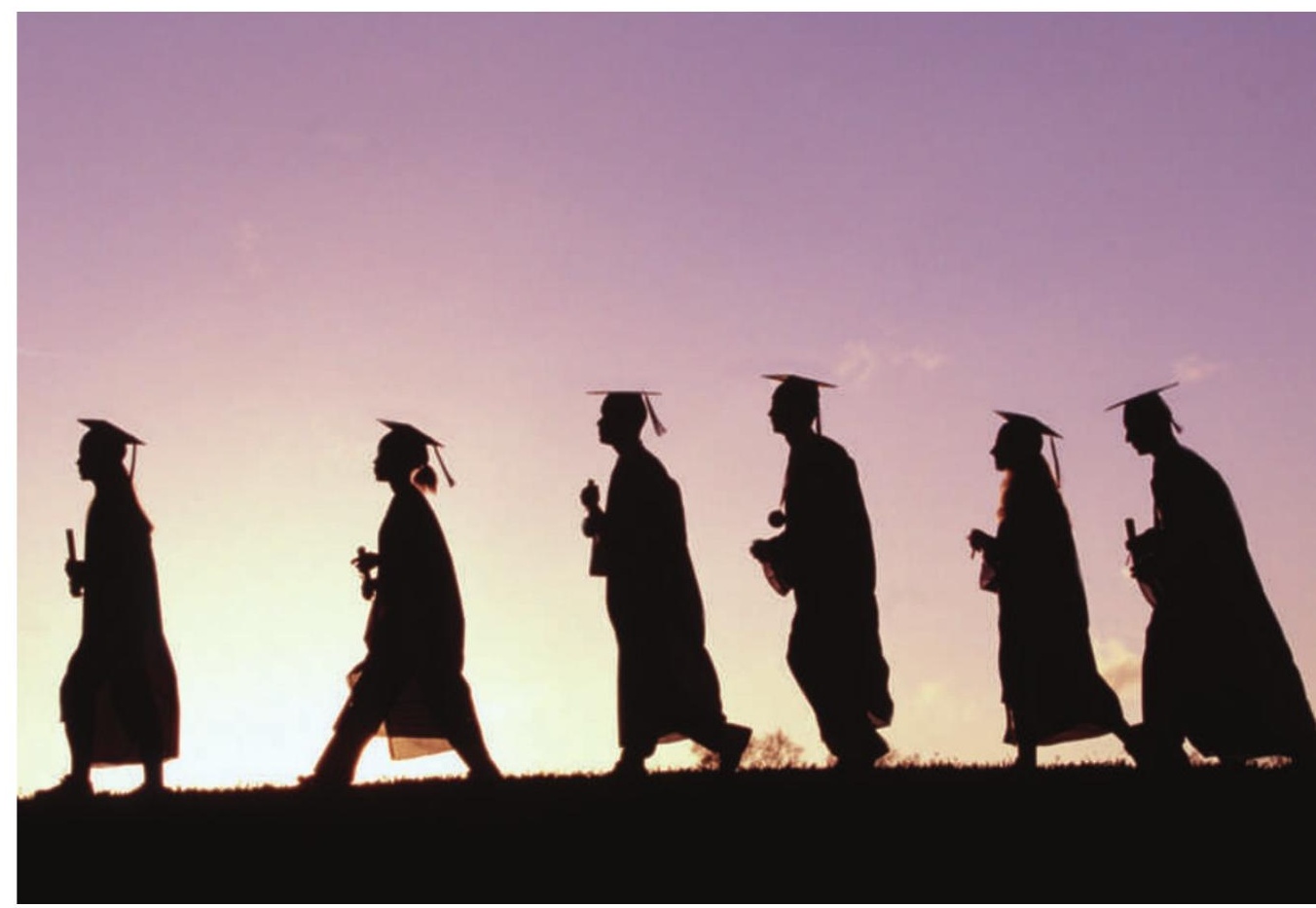

being a student in the natural sciences is good news. Indeed, some top economists believe the absence of a highly skilled workforce is a bigger long-term threat to the economy than the financial crisis.

\section{No need to jump at the first safe job}

In a financial downturn, newly minted PhDs might feel the understandable compulsion to overrate the importance of income and job security. They should worry about those later and make sure they do not accept a secure job that will limit career opportunities in the coming decades. Instead, they should seek a job in which they can acquire new workrelated skills, both scientific and general,

"Economies are cyclic, with a crisis or recession every seven to ten years. The first should be easiest to cope with." and earn exposure to another field that may or may not be in science. Within a couple of years, the economy will probably blossom again, and employers will be desperately looking for qualified people.

Then it will be time for scientists to cash in the work experience and skill set they will have acquired in that less-than-ideal first job in order to achieve better prospects and a good salary.

Given the tight markets in some sectors, postdocs may face the temptation to stay in the same lab another year and continue their $\mathrm{PhD}$ research. Perhaps this means another chance at a scientific breakthrough unrealized during their PhD. Or perhaps there is a chance to acquire additional skills. If so, this might be a convenient way to wait out the crisis. If, on the other hand, scientific advancement or acquisition of new skills seems unlikely, staying may be unwise and they ought to look elsewhere.

New graduates should keep in mind ways in which their first job might benefit their career, even if it is not their science 'dream job'. That first position in the working world will probably be significantly different from their PhD activities. But it is likely to involve working on complex problems that require a variety of skills. That first job probably will also have a major component that involves additional training in such 'soft skills' as giving presentations, writing concise e-mails, conducting meetings or making the most out of informal discussions at the coffee machine. Training on the job, in both hard and soft skills, is essential for advancing a career.

Economies are cyclic, with a crisis or recession coming along every seven to ten years. Most workers will probably face several crises during their careers. Young scientists seeking their first jobs are likely to be the most flexible, with few family constraints and a willingness and ability to move. So their first financial crisis should be easiest to cope with. Bart Noordam is science faculty dean at the University of Amsterdam and Patricia Gosling is a senior manager at Amgen Europe in Zug, Switzerland. They are authors of Mastering Your PhD (Springer Verlag, 2006). 